DIW BERLIN

Discussion

Papers

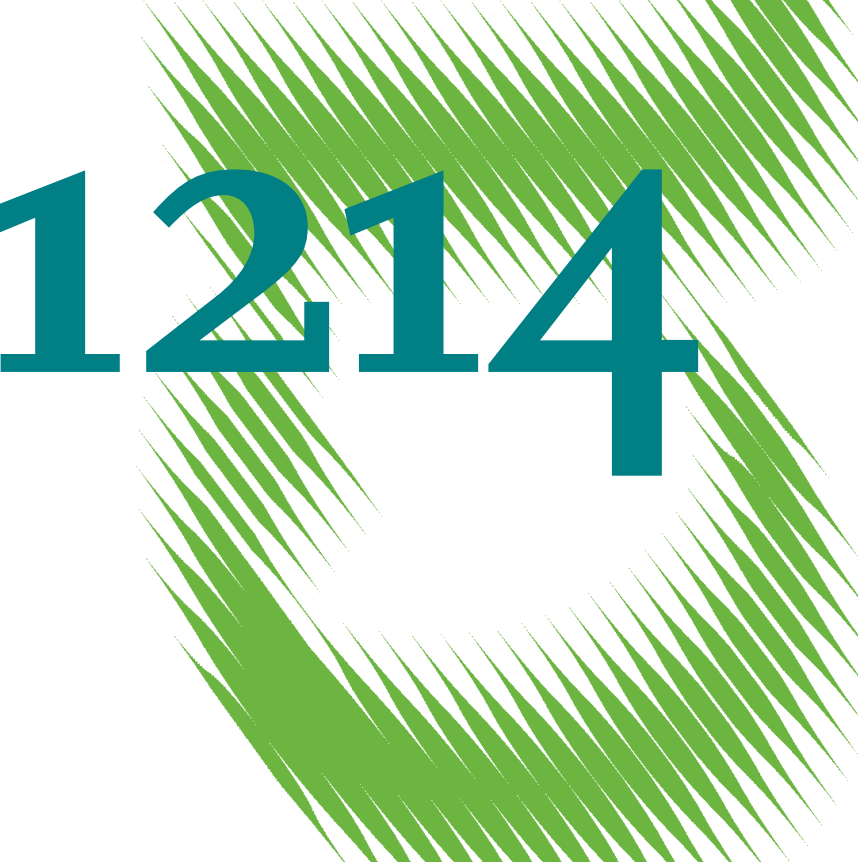

Trade and the Environment: The Role of Firm Heterogeneity 
Opinions expressed in this paper are those of the author(s) and do not necessarily reflect views of the institute.

IMPRESSUM

(C) DIW Berlin, 2012

DIW Berlin

German Institute for Economic Research

Mohrenstr. 58

10117 Berlin

Tel. $+49(30) 89789-0$

Fax +49 (30) $89789-200$

http://www.diw.de

ISSN print edition $1433-0210$

ISSN electronic edition 1619-4535

Papers can be downloaded free of charge from the DIW Berlin website:

http://www.diw.de/discussionpapers

Discussion Papers of DIW Berlin are indexed in RePEc and SSRN:

http://ideas.repec.org/s/diw/diwwpp.html

http://www.ssrn.com/link/DIW-Berlin-German-Inst-Econ-Res.html 


\title{
Trade and the Environment: The Role of Firm Heterogeneity
}

\author{
Udo Kreickemeier* \\ University of Tübingen \\ CESifo and GEP
}

Philipp M. Richter ${ }^{\dagger}$

DIW Berlin

June 1, 2012

\begin{abstract}
This paper derives a new effect of trade liberalisation on the quality of the environment. We show that in the presence of heterogeneous firms the aggregate volume of emissions is influenced not only by the long-established scale effect, but also by a reallocation effect resulting from an increase in the relative size of more productive firms. We show how the relative importance of these effects, and hence the overall effect of trade liberalisation on the environment, is affected by the emission-intensity at the firm level: Aggregate emissions decrease when trade is liberalised if and only if firm-specific emission intensity decreases strongly with increasing firm productivity.
\end{abstract}

JEL codes: F12, F18, Q56

Keywords: Trade and Environment; Monopolistic Competition; Heterogeneous firms;

Environmental Effects

\footnotetext{
${ }^{*}$ University of Tübingen, Faculty of Economics and Social Sciences, Mohlstr. 36, 72074 Tübingen, Germany; Email: udo.kreickemeier@uni-tuebingen.de.

${ }^{\dagger}$ German Institute for Economic Research (DIW Berlin), Mohrenstr. 58, 10117 Berlin, Germany; Email: prichter@diw.de
} 


\section{Introduction}

The recent economic literature has come up with a very useful way to systematically analyse the environmental effects of international trade. According to this now-standard classification, the overall effect of trade liberalisation on aggregate emissions is decomposed into three partial effects: a scale effect resulting from the trade-induced augmentation of economic activity, a technique effect resulting from changed firm-level emission intensities due to endogenous changes in environmental policies, and a composition effect resulting from a trade-induced change in the factor allocation across sectors. ${ }^{1}$ In the theoretical framework predominantly used in this literature, trade occurs due to international differences in relative factor endowments, but the trade pattern may be reversed by differences in country-specific environmental regulation (the pollution haven hypothesis). ${ }^{2}$

In this paper, we theoretically derive a new effect of trade liberalisation on the environment that complements the three effects analysed traditionally. For this purpose, we set up a one-sector model of an open economy with monopolistic competition. Firms differ in their productivity, as in Melitz (2003), and in addition they are heterogeneous with respect to their environmental efficiency. ${ }^{3}$ Pollution is generated during the production process and exerts a direct negative effect on welfare. In line with recent empirical evidence (Cole et al., 2005; Cole

\footnotetext{
${ }^{1}$ This classification has been introduced by Grossman and Krueger (1993) in an empirical paper, while a model-based definition has been provided in a theoretical paper by Copeland and Taylor (1994).

${ }^{2}$ These mechanisms have been well studied empirically. Antweiler et al. (2001) simultaneously estimate the scale, technique, and composition effects of free trade on the concentration of $\mathrm{SO}_{2}$ in more than 40 countries over a time span of 25 years. Their findings suggest, on the one hand, a comparably small composition effect and on the other hand the dominance of positive effects of trade liberalisation on environmental quality, notably driven by the technique effect. Cole and Elliott (2003) derive similar results concerning the reduction of $\mathrm{SO}_{2}$ emissions, but show that the effect of trade liberalisation may be less beneficial for the pollutants $\mathrm{CO}_{2}$ and $\mathrm{NO}_{x}$. Frankel and Rose (2005) account for the potential endogeneity of income and trade volumes. In a recent survey, McAusland (2010) concludes that trade liberalisation may lead to a reduction of local pollutants, whereas the overall impact on global pollutants like greenhouse gases is rather augmenting.

${ }^{3}$ Monopolistic competition models have been somewhat neglected in the trade-and-environment literature. Exceptions include Rauscher (1997), Gürtzgen and Rauscher (2000), Haupt (2000, 2006), and Pflüger (2001). See also the monograph by Copeland and Taylor (2003), and the surveys by Sturm (2003), and more recently Copeland (2011), who all include brief sections discussing models with monopolistic competition.
} 
and Elliott, 2008; Mazzanti and Zoboli, 2009), we assume that more productive firms are also environmentally more efficient. In this setup, trade liberalisation - by benefitting more productive firms with a lower emission intensity disproportionally - affects average emission intensity in the economy via a previously unmodelled reallocation effect. ${ }^{4}$

We show that the overall effect of trade liberalisation on emissions in our framework depends on the relative strength of the traditional scale effect, which leads to an increase in aggregate emissions, ceteris paribus, and the reallocation effect, which leads to a decrease in aggregate emissions, ceteris paribus. The overall effect of freer trade is beneficial for the environment if and only if firm-specific emission intensity decreases strongly with increasing firm productivity.

Although the traditional composition effect and the traditional technique effect are absent from our analysis, the reallocation effect exhibits characteristics of both these traditional effects and can be interpreted as an intra-sectoral version of the former and as an aggregate version of the latter. The remainder of the paper is organised as follows. Section 2 presents the basic model setup. Section 3 derives the open economy equilibrium. The effects of trade liberalisation on the economy and on environmental quality are analysed in Section 4. Section 5 concludes.

\section{$2 \quad$ Model setup}

\subsection{Utility and Demand}

We consider two economies $i$ and $j$ that are open to trade and produce varieties of a differentiated final good, $q$. We will call $i$ the Home country and $j$ the Foreign country in the following. Following Demidova and Rodríguez-Clare (2009), we assume that the Home country is a small open economy, treating country- $j$ variables parametrically. Either economy has a representative

\footnotetext{
${ }^{4}$ Melitz and Trefler (2012) also use this term to describe the rise in allocative intra-industry efficiency due to trade. They do not refer to the impact of trade on the environment, though.
} 
consumer using all his income for consumption of the differentiated good. Preferences of a representative consumer in country $i$ are given by

$$
W_{i}=U_{i}-\eta \mathrm{ED}_{i},
$$

where $U_{i}$ denotes utility consuming a differentiated good, whereas $\eta \mathrm{ED}_{i}$ denotes disutility from environmental damage. Parameter $\eta>0$ reflects the preferences for environmental quality, respectively the tolerance for pollution. Utility function $U_{i}$ in country $i$ is given by:

$$
U_{i}=\left[\int_{v \in V_{i}} q_{i}(v)^{\frac{\sigma-1}{\sigma}} d v\right]^{\frac{\sigma}{\sigma-1}}
$$

where $q_{i}(v)$ denotes demand for variety $v$ in country $i, V_{i}$ is the set of varieties that are available for consumption in $i$, and $\sigma>1$ is the elasticity of substitution between the different varieties of $q$ in consumption. With $R_{i}$ as the expenditure of the representative consumer, and $p_{i}(v)$ as the domestic price of variety $v$, utility maximisation subject to the budget constraint $\int_{v \in V_{i}} p_{i}(v) q_{i}(v) d v=R$ leads to an isoelastic demand function for each variety:

$$
q_{i}(v)=R_{i} P_{i}^{\sigma-1} p_{i}(v)^{-\sigma}
$$

where $P_{i}$ is the standard CES price index in country $i$.

Environmental damage in country $i$ results from domestic and foreign emissions, and for simplicity we specify the linear function

$$
\mathrm{ED}_{i}=\gamma E_{j}+(1-\gamma) E_{i}
$$


where $E_{i}$ and $E_{j}$ denote pollution in countries $i$ and $j$, respectively. The analysis below will focus on country $i$. Due to the small open economy assumption, pollution in $j$ is a parameter from country $i$ 's point of view. Parameter $\gamma \in[0,1]$ is a measure for the degree of "transboundariness" of a particular pollutant, where $\gamma=0$ denotes the case of a purely local pollutant, and $\gamma=1$ the case of a global one.

\subsection{Production}

There is a continuum of firms, each producing one unique variety. Homogeneous labour is the only factor of production, the labour market is perfectly competitive, and the equilibrium wage rate in country $i$ is denoted by $w_{i}$. The mass of domestic producers in country $i$ is given by $M_{i}^{d}$ and together with exporters $M_{j}^{x}$ from country $j(j \neq i)$ these firms add up to the mass of producers that serve the domestic market: $M_{i}^{t}=M_{i}^{d}+M_{j}^{x}$. Firm entry into each market is described in section 3 below. The goods market in either country is characterised by monopolistic competition, implying that firms take aggregate variables as given, while they set prices as a monopolist in the market for their own variety. In order to produce and distribute their output, firms have a (periodical) fixed cost $w_{i} f$. The output of each firm is linear in variable labour input $l_{i}^{v}$ and depends on the firm-specific productivity level $\varphi: q_{i}=\varphi l_{i}^{v}$. Denoting the marginal cost of selling variety $v$ in market $i$ by $c_{i}(v)$, the solution to a firm's price-setting problem is given by the constant markup rule:

$$
p_{i}(v)=\frac{c_{i}(v)}{\rho}
$$

where $\rho \equiv(\sigma-1) / \sigma$. Unit costs of selling in market $i$ are equal to unit production costs $\tilde{c}_{i}(v)=w_{i} / \varphi(v)$ for domestic varieties. Imported varieties are subject to an ad valorem tariff 
at rate $\tau$, and therefore $c_{i}(v) \equiv(1+\tau) \tilde{c}_{j}(v)$ for imported varieties. From (3) and (5), domestic revenues and profits, respectively, of a country- $i$ firm with productivity $\varphi$ are given by

$$
r_{i}^{d}(\varphi)=R_{i} P_{i}^{\sigma-1}\left(\frac{w_{i}}{\rho \varphi}\right)^{1-\sigma} \quad \text { and } \quad \pi_{i}^{d}(\varphi)=\frac{r_{i}^{d}(\varphi)}{\sigma}-w_{i} f
$$

Comparing two arbitrary firms 1 and 2 based in country $i$, and using the relationship between firm-level revenues, output, and employment just derived, it follows directly that relative domestic outputs, revenues, and variable employment levels of these firms are proportional to their relative productivities, a result well known from Melitz (2003):

$$
\frac{q_{i}\left(\varphi_{1}\right)}{q_{i}\left(\varphi_{2}\right)}=\left(\frac{\varphi_{1}}{\varphi_{2}}\right)^{\sigma} \quad \frac{r_{i}^{d}\left(\varphi_{1}\right)}{r_{i}^{d}\left(\varphi_{2}\right)}=\frac{l_{i}^{v}\left(\varphi_{1}\right)}{l_{i}^{v}\left(\varphi_{2}\right)}=\left(\frac{\varphi_{1}}{\varphi_{2}}\right)^{\sigma-1}
$$

Exporting firms from country $i$ have to bear a second fixed cost, $w_{i} f^{x}$, but variable trade costs are zero. Country $j$ is assumed to be large in the sense that country- $i$ firms treat market size $A \equiv R_{j} P_{j}^{\sigma-1}$ parametrically. In analogy to (3), demand from country $j$ for country- $i$ exports is given by

$$
q_{j}(v)=A p_{i}(v)^{-\sigma}
$$

and the export revenues and profits follow as

$$
r_{i}^{x}(\varphi)=A\left(\frac{w_{i}}{\rho \varphi}\right)^{1-\sigma} \quad \text { and } \quad \pi_{i}^{x}(\varphi)=\frac{r_{i}^{x}(\varphi)}{\sigma}-w_{i} f^{x}
$$

respectively. The comparison of Eqs. (6) and (9) shows that firm-level export revenues are proportional to domestic revenues, and one can easily show that this proportionality also holds 
for output and variable employment levels. Hence, the results in Eq. (7) are also valid for the ratio of two firms' total outputs, revenues, and variable employment levels, provided these firms have the same export status.

Finally, export revenues and export profits by country- $j$ exporters are given by

$$
r_{i}^{m}=\frac{1}{1+\tau}\left[R_{i} P_{i}^{\sigma-1}\left(\frac{(1+\tau) w_{j}}{\rho \varphi^{m}}\right)^{1-\sigma}\right] \quad \text { and } \quad \pi_{i}^{m}=\frac{r_{i}^{m}}{\sigma}-F^{x}
$$

respectively, where $F^{x}$ are country- $j$ firms' export costs. Note that $\tau$ enters the expression for export revenues of country- $j$ firms twice: First, it appears in the term in brackets since it affects the domestic consumer price and the implied quantity demanded. The term in square brackets then gives gross export revenues (including tariff payments), which have to be divided by $1+\tau$ in order to give net export revenues.

\subsection{Emissions}

Pollution is emitted by each firm as a joint output of production. An individual firm with productivity $\varphi$ in country $i$ emits pollution according to:

$$
e_{i}(\varphi)=\frac{1}{\varphi^{\alpha}} \cdot \begin{cases}q_{i}(\varphi) & \text { if firm does not export } \\ {\left[q_{i}(\varphi)+q_{j}(\varphi)\right]} & \text { if firm exports }\end{cases}
$$

The emission intensity $1 / \varphi^{\alpha}$ is defined as the amount of pollution per unit of output, and as parametrised in Eq. (11) it changes monotonically with firm-specific productivity $\varphi$, where the extent to which this is the case depends on technology parameter $\alpha \geq 0$. The higher $\alpha$, the 
stronger the decline in emission intensity in more productive firms. ${ }^{5}$ Formally, it follows from (7) that for two firms of the same trade status relative emissions are given by:

$$
\frac{e_{i}\left(\varphi_{1}\right)}{e_{i}\left(\varphi_{2}\right)}=\left(\frac{\varphi_{1}}{\varphi_{2}}\right)^{\sigma-\alpha}
$$

There are some interesting special cases. In the borderline case of $\alpha=0$, emission intensity is independent of firm productivity, and hence firm-specific emissions are directly proportional to output. With $\alpha=1$, emissions are proportional to variable labour input. Since more productive firms employ more workers (given the status as exporter or non-exporter, respectively), highproductivity firms in this case still have higher total emissions than low-productivity firms. With $\alpha=\sigma$, the reduction in emission intensity in more productive firms is sufficiently strong to fully compensate the higher output, and the total emissions per firm, given its status as exporter or non-exporter, respectively, are independent of firm productivity.

\section{Open economy equilibrium}

Firm entry into domestic production and into exporting is modeled as is standard in Melitz-type models: There is an unbounded pool of entrants deciding on paying a fixed market entry cost $w_{i} f^{e}$, which is immediately sunk, that allows them to draw labour productivity from the common distribution $G_{i}(\varphi)$. Knowing their productivity, they then decide whether to start producing, and which markets (only domestic, or domestic and foreign) to serve. Fixed export costs $w_{i} f^{x}$ ensure that only a subset of the domestic firms finds it profitable to export, and similarly due to foreign export costs $F^{x}$ only a subset of foreign firms serves the domestic market. There is

\footnotetext{
${ }^{5}$ This is in line with recent empirical findings (cf. Cole et al., 2005; Cole and Elliott, 2008; Mazzanti and Zoboli, 2009) that suggest a positive correlation between productivity and environmental efficiency.
} 
an infinite number of time periods, and every period an exogenous fraction $\delta$ of firms is hit by a negative shock and has to stop production. We focus on a steady-state equilibrium, in which the mass of firms is constant over time.

Firm productivities $\varphi$ are Pareto distributed, with the lower bound normalised to one without loss of generality: $G_{i}(\varphi)=1-\varphi^{-k}$ and $g(\varphi)=k \varphi^{-(k+1)}$, where we assume that $k>\sigma$ holds in order to ensure that average per-firm output is finite. ${ }^{6}$ With the ex ante productivity distribution being Pareto, also the ex post productivity distributions of active firms, $\mu^{d}(\varphi)$, and of active exporting firms, $\mu^{x}(\varphi)$, are Pareto, with the respective lower bound being given by the productivity of the marginal domestic firm, $\varphi^{d}$, and the productivity of the marginal exporting firm, $\varphi^{x}$ :

$$
\mu^{d}(\varphi)=\frac{k}{\varphi}\left(\frac{\varphi^{d}}{\varphi}\right)^{k} \quad \mu^{x}(\varphi)=\frac{k}{\varphi}\left(\frac{\varphi^{x}}{\varphi}\right)^{k}
$$

Similarly, foreign exporting firms are Pareto distributed as well, with the productivity of the least productive foreign exporter (domestic importer) denoted by $\varphi^{m}$. Using the Pareto distribution, the free entry condition is given by

$$
\left(\varphi^{d}\right)^{-k} \frac{\bar{\pi}_{i}}{\delta}=w_{i} f^{e}
$$

where $\bar{\pi}_{i}$ are the average profits of all active firms, and $\left(\varphi^{d}\right)^{-k}$ is the ex-ante probability of a successful draw. The left hand side gives the present value of expected profits from the point of view of a firm that does not yet know its productivity, and in equilibrium this value has to be equal to the cost of entering the productivity draw.

\footnotetext{
${ }^{6} \mathrm{~A}$ Pareto distribution of firm productivities is commonly used in the literature following Melitz (2003) (although not in the original paper by Melitz). Eaton et al. (2011), among others, document that this distributional assumption provides a good approximation for the right tail in the empirical distribution of firm sizes.
} 


\subsection{Zero profit conditions and economy averages}

There are three zero profit conditions, each giving a general equilibrium relationship between the respective cutoff productivity $\left(\varphi^{d}, \varphi^{x}\right.$, and $\left.\varphi^{m}\right)$, the fixed labour requirement of entering the respective market, and endogenous economy-wide variables:

$$
\begin{aligned}
\frac{1}{\sigma}\left[R_{i} P_{i}^{\sigma-1}\left(\frac{w_{i}}{\rho \varphi^{d}}\right)^{1-\sigma}\right] & =w_{i} f, \\
\frac{1}{\sigma}\left[A\left(\frac{w_{i}}{\rho \varphi^{x}}\right)^{1-\sigma}\right] & =w_{i} f^{x}, \\
\frac{1}{\sigma(1+\tau)}\left[R_{i} P_{i}^{\sigma-1}\left(\frac{(1+\tau) w_{j}}{\rho \varphi^{m}}\right)^{1-\sigma}\right] & =F^{x},
\end{aligned}
$$

where we have used the definition of profits in Eqs. (6), (9), and (10). On the left hand side in all three equations are the operating profits of the lowest-productivity firm serving the respective market, and they are set equal to the fixed cost of serving this market.

The zero profit conditions can now be used to derive simple expressions for averages across firms for key economic variables. First, average output for the domestic market and the export market, respectively, are given by:

$$
\begin{gathered}
\bar{q}_{i}^{d}=\int_{\varphi^{d}}^{\infty} q_{i}^{d}(\varphi) \mu^{d}(\varphi) d \varphi=\left(\frac{k(\sigma-1)}{k-\sigma}\right) f \varphi^{d} \\
\bar{q}_{i}^{x}=\int_{\varphi^{x}}^{\infty} q_{i}^{x}(\varphi) \mu^{x}(\varphi) d \varphi=\left(\frac{k(\sigma-1)}{k-\sigma}\right) f^{x} \varphi^{x},
\end{gathered}
$$

where we have substituted from Eqs. (6), (9), and (13). ${ }^{7}$ Using the link between firm-level output and firm-level emissions given by Eq. (11), average per-firm emissions due to production

\footnotetext{
${ }^{7}$ The details of the derivation are deferred to the appendix.
} 
for the domestic and export markets can be analogously derived as:

$$
\bar{e}_{i}^{d}=\left(\frac{k(\sigma-1)}{\alpha+k-\sigma}\right) f\left(\varphi^{d}\right)^{\alpha-1} \quad \bar{e}_{i}^{x}=\left(\frac{k(\sigma-1)}{\alpha+k-\sigma}\right) f^{x}\left(\varphi^{x}\right)^{\alpha-1}
$$

Using the same procedure as in the derivation of Eq. (18), average domestic revenues and export revenues, respectively, can be computed as

$$
\bar{r}_{i}^{d}=\Theta \sigma w_{i} f \quad \bar{r}_{i}^{x}=\Theta \sigma w_{i} f^{x}
$$

where we have defined $\Theta \equiv k /[k-(\sigma-1)]>1$. Lastly, average profits for all firms in the economy can be written, following Eq. (20), as:

$$
\bar{\pi}_{i}=(\Theta-1) w_{i}\left[f+\left(\frac{\varphi^{d}}{\varphi^{x}}\right)^{k} f^{x}\right]
$$

where $\left(\varphi^{d} / \varphi^{x}\right)^{k}$ is the share of domestic firms that export.

\subsection{Aggregate variables}

In general equilibrium, domestic labour needs to be fully employed. Taking into account labour's potential employment in market entry, as well as in production for the domestic market and for export, the full employment condition is written as

$$
M_{i}^{e} f^{e}+M_{i}^{d} f+M_{i}^{x} f^{x}+M_{i}^{d} \int_{\varphi^{d}}^{\infty} \frac{q_{i}(\varphi)}{\varphi} \mu^{d}(\varphi) d \varphi+M_{i}^{x} \int_{\varphi^{x}}^{\infty} \frac{q_{j}(\varphi)}{\varphi} \mu^{x}(\varphi) d \varphi=L_{i}
$$

where $M_{i}^{e}$ is the mass of firms entering the productivity draw, and $L_{i}$ is the exogenous labour supply of country $i$. Using the equilibrium stability condition $\left(\varphi^{d}\right)^{-k} M_{i}^{e}=\delta M_{i}^{d}$ (the mass 
of firms taking up production is equal to the mass of firms stopping production), the identity $M_{i}^{x}=\left(\varphi^{d} / \varphi^{x}\right)^{k} M_{i}^{d}$, as well as Eqs. (14) to (16) and (20), it is possible to solve for the mass of domestic firms and domestic exporters, respectively, as: ${ }^{8}$

$$
M_{i}^{d}=\Omega_{i}\left(\varphi^{d}\right)^{-k} \quad M_{i}^{x}=\Omega_{i}\left(\varphi^{x}\right)^{-k}
$$

where $\Omega_{i} \equiv \rho L_{i} /\left(k \delta f^{e}\right)$ is a measure of market size.

Aggregate output $Q_{i}$ is given by $M_{i}^{d} \bar{q}_{i}^{d}+M_{i}^{x} \bar{q}_{i}^{x}$, and substituting from Eqs. (18) and (23) we get:

$$
Q_{i}=\Omega_{i}\left(\frac{k(\sigma-1)}{k-\sigma}\right)\left(\frac{f}{\left(\varphi^{d}\right)^{k-1}}+\frac{f^{x}}{\left(\varphi^{x}\right)^{k-1}}\right)
$$

and hence aggregate output is higher the lower the domestic cutoff productivity, and the lower the foreign cutoff productivity, ceteris paribus. ${ }^{9}$

Aggregate domestic emissions can be derived in analogy to aggregate output as

$$
E_{i}=\Omega_{i}\left(\frac{k(\sigma-1)}{\alpha+k-\sigma}\right)\left(\frac{f}{\left(\varphi^{d}\right)^{\alpha+k-1}}+\frac{f^{x}}{\left(\varphi^{x}\right)^{\alpha+k-1}}\right)
$$

Aggregate domestic emissions are hence determined by the technical parameter $\alpha$ as well as by the equilibrium levels of the domestic entry and the export cutoff productivities $\varphi^{d}$ and $\varphi^{x}$.

\footnotetext{
${ }^{8}$ See the appendix for a detailed derivation.

${ }^{9}$ Aggregate output $Q_{i}$ as defined in Eq. (24) is not usually considered a variable of interest in Melitz-style trade models with hetereogeneous firms, since welfare depends on the CES-aggregate of firm-specific outputs, rather than on their simple sum. $Q_{i}$ is a relevant variable in the present context though, since in our framework a change in $Q_{i}$ is the natural measure of the scale effect.
} 


\subsection{Cutoff productivities}

Having derived aggregate variables as a function of the various productivity cutoffs, we now turn to determining the cutoffs themselves. To this end, we make use of the free entry condition Eq. (14) together with average profits Eq. (21) to get

$$
\varphi^{x}=\left(\frac{f^{x}}{\delta f^{e} /(\Theta-1)-f /\left(\varphi^{d}\right)^{k}}\right)^{\frac{1}{k}}
$$

While not an explicit solution for either cutoff, Eq. (26) gives a link between the two productivity cutoffs $\varphi^{x}$ and $\varphi^{d}$ that only depends on model parameters. It is immediate that a higher domestic productivity cutoff is accompanied in equilibrium by a lower export productivity cutoff, with the respective elasticity given by

$$
\varepsilon_{x d} \equiv \frac{\partial \varphi^{x}}{\partial \varphi^{d}} \frac{\varphi^{d}}{\varphi^{x}}=-\frac{f}{f^{x}}\left(\frac{\varphi^{x}}{\varphi^{d}}\right)^{k}<0
$$

A second link between the two cutoff productivities can be derived from the trade balance condition, which states that the value of exports at world market prices (identical to the export revenue of country- $i$ firms) is equal to the value of imports at world market prices (identical to the export revenue of country- $j$ firms). Using Eq. (20), the trade balance condition can be written as

$$
M_{i}^{x} w_{i} f^{x}=M_{j}^{x} F^{x}
$$

It is shown in the appendix that after substituting for endogenous variables $M_{i}^{x}, M_{j}^{x}$ and $w_{i}$, 
and some straightforward but tedious algebra, we get

$$
\varphi^{x}=B(1+\tau)^{\frac{k}{(2 k-\rho) \rho}}\left(\varphi^{d}\right)^{\frac{k}{2 k-\rho}},
$$

where $B$ is a positive constant. Eq. (29) links the two productivity cutoffs $\varphi^{d}$ and $\varphi^{x}$ to the policy parameter $\tau$, and we can use Eq. (26) to substitute for either cutoff productivity. We choose to substitute for $\varphi^{x}$, and arrive at implicit function

$$
F\left(\varphi^{d}, \tau\right)=\frac{\delta f^{e}}{(\Theta-1)}\left(\varphi^{d}\right)^{\frac{k^{2}}{2 k-\rho}}-f\left(\varphi^{d}\right)^{\frac{-\left(k^{2}-k \rho\right)}{2 k-\rho}}-f^{x} B^{-k}(1+\tau)^{\frac{-k^{2}}{(2 k-\rho) \rho}} \equiv 0
$$

linking domestic cutoff productivity $\varphi^{d}$ and the import tariff $\tau$.

\section{Trade liberalisation}

Trade liberalisation is modelled as the unilateral reduction of the domestic tariff $\tau$. Implicit differentiation of Eq. (30) gives

$$
\frac{\partial \varphi^{d}}{\partial \tau}=-\frac{\partial F / \partial \tau}{\partial F / \partial \varphi^{d}}
$$

and, as formally shown in the appendix, we have $\partial \varphi^{d} / \partial \tau<0 .{ }^{10}$ Hence, more liberal trade increases the domestic cutoff productivity. The effect on the export cutoff productivity follows from combining Eqs. (31) and (27):

$$
\frac{\partial \varphi^{x}}{\partial \tau}=\varepsilon_{x d} \frac{\varphi^{x}}{\varphi^{d}} \frac{\partial \varphi^{d}}{\partial \tau}=-\frac{f}{f^{x}}\left(\frac{\varphi^{x}}{\varphi^{d}}\right)^{k+1} \frac{\partial \varphi^{d}}{\partial \tau}>0
$$

\footnotetext{
${ }^{10}$ See Demidova and Rodríguez-Clare (2009) for an alternative proof.
} 
and hence a higher degree of trade openness reduces the productivity level of the marginal exporter. The intuition behind the effect of trade liberalisation on both domestic and export cutoffs is straightforward (Demidova and Rodríguez-Clare, 2009): Consumer expenditure shifts towards imported varieties, which leads to an exit of the least productive firms. The direct effect of this exit is to increase the domestic productivity cutoff. But due to the labour released by the exiting firms the equilibrium wage $w_{i}$ decreases, and the most productive non-exporting firms become competitive on the export market, implying a decrease in the export productivity cutoff.

Turning to the effect of trade liberalisation on aggregate output, we get

$$
\frac{\partial Q_{i}}{\partial \tau}=\left(\frac{\partial Q_{i}}{\partial \varphi^{d}}+\frac{\partial Q_{i}}{\partial \varphi^{x}} \frac{\partial \varphi^{x}}{\partial \varphi^{d}}\right) \frac{\partial \varphi^{d}}{\partial \tau}
$$

The sign of the term in brackets ultimately decides on the overall impact on aggregate production. We know from Eqs. (24) and (27) that the first term is negative, while the second term is positive: On the one hand, trade liberalisation, by increasing the domestic cutoff productivity, has a negative impact on production for the domestic market. On the other hand, by lowering the export cutoff productivity, it increases the output destined for the export market. Substituting for the three partial derivatives, we get

$$
\operatorname{sign}\left(\frac{\partial Q_{i}}{\partial \varphi^{d}}+\frac{\partial Q_{i}}{\partial \varphi^{x}} \frac{\partial \varphi^{x}}{\partial \varphi^{d}}\right)=-\operatorname{sign}\left(\frac{\partial Q_{i} / \partial \varphi^{d}}{\partial Q_{i} / \partial \varphi^{x}}+\frac{\partial \varphi^{x}}{\partial \varphi^{d}}\right)=\operatorname{sign}\left[\left(\frac{\varphi^{x}}{\varphi^{d}}\right)^{k+1}-\left(\frac{\varphi^{x}}{\varphi^{d}}\right)^{k}\right]
$$

and since $\varphi^{x}>\varphi^{d}$ the term in brackets is positive, which implies that trade liberalisation increases aggregate output.

Domestic environmental quality is determined by exogenous foreign emissions and domestic 
pollution. The latter changes with trade liberalisation according to

$$
\frac{\partial E_{i}}{\partial \tau}=\left(\frac{\partial E_{i}}{\partial \varphi^{d}}+\frac{\partial E_{i}}{\partial \varphi^{x}} \frac{\partial \varphi^{x}}{\partial \varphi^{d}}\right) \frac{\partial \varphi^{d}}{\partial \tau}
$$

and in analogy to the case of aggregate output we can compute

$$
\operatorname{sign}\left(\frac{\partial E_{i}}{\partial \varphi^{d}}+\frac{\partial E_{i}}{\partial \varphi^{x}} \frac{\partial \varphi^{x}}{\partial \varphi^{d}}\right)=\operatorname{sign}\left[\left(\frac{\varphi^{x}}{\varphi^{d}}\right)^{k+1}-\left(\frac{\varphi^{x}}{\varphi^{d}}\right)^{k+\alpha}\right]
$$

Hence, trade liberalisation increases domestic emissions if and only if the technology parameter $\alpha$ is smaller than 1 . We summarise our key result as follows:

Proposition. The effect of trade liberalisation on aggregate emissions is uniquely determined by technology parameter $\alpha$, governing the relative emission intensity of firms. Trade liberalisation reduces aggregate emissions in a small open economy via a reallocation of resources to more productive firms if and only if $\alpha>1$, and therefore emission intensities decrease strongly with firm productivity.

The economic intuition for the effect of trade liberalisation on the environment is as follows. Aggregate domestic emissions $E_{i}$ are affected via two channels. First, a scale effect familiar from Grossman and Krueger (1993) increases pollution in accordance with increased aggregate output. Second, trade liberalisation leads to a reallocation of production towards more productive firms, which produce with a lower firm-specific pollution intensity. This reallocation effect reduces aggregate emissions, ceteris paribus. For $\alpha=1$, these two opposing effects exactly offset each other, whereas for any value of $\alpha$ larger than 1, the reallocation effect dominates the scale effect, and total domestic emissions are smaller in a more open economy.

An interesting case arises for the range of $\alpha$ between 1 and $\sigma$. On the one hand, the 
reallocation effect dominates the scale effect, and aggregate domestic emissions unambiguously decrease. On the other hand, however, more productive firms generate more emissions, as can be deduced from Eq. (12). This shows that freer trade can be favorable for the environment, even if trade liberalisation leads to a reallocation of resources to those firms that - due to their larger scale - generate more emissions. The scenario of $1<\alpha<\sigma$ well matches recent empirical findings. It features an overall trade-induced reduction of pollution (Antweiler et al., 2001; McAusland, 2010), and lower emissions of exporters relative to non-exporting competitors when (crucially) controlling for output (Holladay, 2010).

It is instructive to relate the effect of trade liberalisation on emissions in the heterogeneous firm framework to the effects derived in the traditional literature. Both the traditional technique effect and the traditional composition effect are absent from our analysis: the first because we abstract from environmental policy, and the second because our model has only a single sector. However, our newly identified reallocation effect can be alternatively interpreted as either one of these effects: Although the pollution intensity of an individual firm remains unchanged when trade is liberalised, the average pollution intensity of the industry is reduced in accordance with an increase in the average productivity. Or, put differently, the technique effect can be identified for the aggregate sector. Alternatively, the reallocation effect can be interpreted as an intrasectoral composition effect. Trade leads to a change in the market structure within the analysed sector. Labor is reallocated to the most productive firms, which are, under the assumption of a positive relation between labour productivity and environmental efficiency, the firms with the lowest emission intensities. ${ }^{11}$

\footnotetext{
${ }^{11}$ Copeland (2010, p. 209) informally describes an intra-sectoral version of the composition effect as follows: "There are also firm-level effects: the recent international trade literature has emphasised that only the most productive firms tend to export and so trade tends to cause some firms to expand and others to contract or exit. [...] If emission intensities vary across industries [and] firms [...] then these composition effects will have a direct influence on environmental outcomes."
} 
Notably, the reallocation effect leads to a reduction of emissions in all trading countries, ceteris paribus. In contrast, the traditional inter-sectoral composition effect has to be of opposite sign between the trading countries since it relies on comparative advantage. By specializing in the production of the pollution intensive good, one country has necessarily to bear an increase in pollution due to the composition effect.

We finally turn briefly to a discussion of the effect that trade liberalisation has on welfare, i.e. the utility of the representative consumer given by Eq. (1). Demidova and Rodríguez-Clare (2009) have shown that the optimal tariff for the present small open economy setting, but without emissions, is equal to $\tau^{o}=\rho /(k-\rho)>0$, and in fact that this tariff leads to a first best equilibrium. The optimal tariff in this case corrects the two distortions present in the model, namely the mark-up distortion (consumer prices reflect the opportunity cost of imported products in free trade, but they exceed the resource cost of domestic products by the monopolistic markup) and the consumer surplus externality (higher import spending increases the mass of available imported varieties, an effect ignored by the individual allocating his expenditure). Eqs. (1) and (4) show that this result is modified in a straightforward way in the present context, in which domestic production causes emissions. Whenever $\gamma<1$, and therefore domestic emissions cause non-negligible domestic environmental damage, the value for the optimal tariff deviates from $\tau^{o}=\rho /(k-\rho)$ in a well-defined way: Starting from $\tau^{o}$, small deviations have only a secondorder effect on the two non-environmental distortions (this is what makes the tariff optimal in the setting of Demidova and Rodríguez-Clare (2009) to begin with), and hence the optimal direction to deviate is the one that leads to lower domestic emissions. This - as shown above - in turn depends on technology parameter $\alpha$ : a tariff increase reduces emissions for $\alpha<1$, whereas a tariff reduction reduces emissions for $\alpha>1$. The optimal tariff is therefore smaller 
than $\tau^{o}$ for the empirically plausible case $\alpha>1$, and larger than $\tau^{o}$ otherwise.

\section{Conclusion}

The traditional literature derives three principal channels through which trade liberalisation affects the environment: an emission increasing scale effect due to an augmentation of economic activity, an emission reducing technique effect arising from changes in emission intensities, following stricter environmental policies, and a composition effect, whose sign and strength depends on comparative advantages of the considered country. The latter effect is the consequence of a change in a country's industrial structure due to specialisation.

In this paper we have shown that by means of a trade model with monopolistic competition and heterogeneous firms a fourth principal channel can be derived. By positively linking a firm's productivity to its environmental efficiency, the trade-induced increase in aggregate productivity translates into a reduction of aggregate pollution intensity. The least productive firms exit the market, resources are reallocated towards the most productive and least pollution intensive firms. This reallocation effect reduces aggregate domestic emissions, ceteris paribus, but due to the presence of the scale effect the overall impact of freer trade on total pollution is negative if and only if firm-specific emission intensity decreases strongly with increasing firm productivity. While in our model both, the traditional composition effect and the traditional technique effect are absent, the reallocation effect can be interpreted as an intra-sectoral composition effect and as a technique effect for the aggregate sector.

Since the model has only one sector and one factor of production, determinants of comparative advantage and the resulting consequences on environmental quality cannot be addressed. Hence, a potentially worthwhile extension would be to embed the present framework of a mo- 
nopolistically competitive sector with heterogeneous firms into a model of the Heckscher-Ohlin type à la Bernard et al. (2007).

\section{Appendix}

\section{Computing average output}

Average domestic output $\bar{q}_{i}^{d}$ can be calculated by means of the ex post productivity distribution of active firms, given in Eq. (13) as follows:

$$
\begin{aligned}
\bar{q}_{i}^{d} & =\int_{\varphi^{d}}^{\infty} q_{i}^{d}(\varphi) \mu^{d}(\varphi) d \varphi=\int_{\varphi^{d}}^{\infty} R_{i} P_{i}^{\sigma-1}\left(\frac{w_{i}}{\rho \varphi}\right)^{-\sigma} \mu^{d}(\varphi) d \varphi \\
& =R_{i} P_{i}^{\sigma-1}\left(\frac{w_{i}}{\rho}\right)^{-\sigma} k\left(\varphi^{d}\right)^{k} \int_{\varphi^{d}}^{\infty} \varphi^{\sigma-k-1} d \varphi \\
& =\left(\frac{k}{k-\sigma}\right) R_{i} P_{i}^{\sigma-1}\left(\frac{w_{i}}{\rho \varphi^{d}}\right)^{-\sigma} \\
& =\left(\frac{k}{k-\sigma}\right)(\sigma-1) f \varphi^{d},
\end{aligned}
$$

where the last equation follows from zero cutoff profit condition Eq. (15). Average output produced for the export market can be calculated analogously, using zero cutoff profit condition Eq. (16)

\section{Mass of incumbent firms}

The full employment condition given in Eq. (22) can be simplified by using $M_{i}^{e}=\delta\left(\varphi^{d}\right)^{k} M_{i}^{d}$ and $M_{i}^{x}=\left(\varphi^{d} / \varphi^{x}\right)^{k} M_{i}^{d}$ as well as Eqs. (15) and (16) to solve the integrals.

$$
M_{i}^{d}\left[\delta f^{e}\left(\varphi^{d}\right)^{k}+f+\left(\frac{\varphi^{d}}{\varphi^{x}}\right)^{k} f^{x}+\Theta(\sigma-1) f+\left(\frac{\varphi^{d}}{\varphi^{x}}\right)^{k} \Theta(\sigma-1) f^{x}\right]=L_{i}
$$


Rearranging terms, yields:

$$
M_{i}^{d}\left[\delta f^{e}\left(\varphi^{d}\right)^{k}+(1+\Theta(\sigma-1))\left(f+\left(\frac{\varphi^{d}}{\varphi^{x}}\right)^{k} f^{x}\right)\right]=L_{i} .
$$

Now we can use average profits (21) to get

$$
M_{i}^{d}\left[\delta f^{e}\left(\varphi^{d}\right)^{k}+(1+\Theta(\sigma-1))\left(\frac{\bar{\pi}_{i}}{w(\Theta-1)}\right)\right]=L_{i}
$$

By mean of the free entry condition (14) this can be rewritten as

$$
M_{i}^{d}\left[\delta f^{e}\left(\varphi^{d}\right)^{k}\left(1+\frac{1+\Theta(\sigma-1)}{\Theta-1}\right)\right]=L_{i}
$$

Noting that $\Theta \sigma /(\Theta-1)=k / \rho$, this becomes

$$
M_{i}^{d}\left(\frac{\delta f^{e} k}{\rho}\left(\varphi^{d}\right)^{k}\right)=L_{i}
$$

The last equation can easily be solved for the mass of incumbent firms $M_{i}^{d}$. Applying the share of exporters $\left(\varphi^{d} / \varphi^{x}\right)^{k}$, then gives the mass of exporting firms $M_{i}^{x}$.

\section{Derivation of Eq. (29)}

The trade balance condition

$$
\operatorname{Exp} \equiv M_{i}^{x} \int_{\varphi^{x}}^{\infty} r_{i}^{x}(\varphi) \mu^{x}(\varphi) d \varphi=M_{j}^{x} \int_{\varphi^{m}}^{\infty} r_{j}^{x}(\varphi) \mu^{m}(\varphi) d \varphi \equiv \operatorname{Imp}
$$

can be rewritten as Eq. (28) in the text by using average revenues given in Eq. (20). Recalling 
that $M_{j}^{x}=\left(\varphi^{m}\right)^{-k}$ and using the expression for $M_{i}^{x}$ in Eq. (23) we get

$$
\left(\varphi^{m}\right)^{-k}=\frac{f^{x}}{F^{x}} \Omega_{i}\left(\varphi^{x}\right)^{-k} w_{i}
$$

Rewriting the zero export cutoff profit condition Eq. (16) we can express the endogenous wage rate as a function of the export cutoff

$$
w_{i}=\left(\frac{A}{\sigma f^{x}}\right)^{\frac{1}{\sigma}}\left(\rho \varphi^{x}\right)^{\rho}
$$

The substitution of Eq. (A.9) into Eq. (A.8) leads to an expression for the import cutoff productivity $\varphi^{m}$ as a positive function of the export cutoff productivity $\varphi^{x}$ alone, i.e.

$$
\varphi^{m}=\left(\frac{\Omega_{i} \rho^{\rho}\left(f^{x}\right)^{\rho}}{F^{x}}\left(\frac{A}{\sigma}\right)^{\frac{1}{\sigma}}\right)^{-\frac{1}{k}}\left(\varphi^{x}\right)^{\frac{k-\rho}{k}}
$$

Dividing Eq. (15) by Eq. (17), and substituting for $w_{i}$ from Eq. (A.9), we furthermore get

$$
\varphi^{m}=(1+\tau)^{\frac{1}{\rho}}\left(\frac{\sigma f^{x} F^{x}}{A f}\right)^{\frac{1}{\sigma-1}} \frac{w_{j}}{\rho} \frac{\varphi^{d}}{\varphi^{x}} .
$$

Using Eqs. (A.10) and (A.11), one can eliminate the import cutoff productivity $\varphi^{m}$, and gets Eq. (29) in the main text, where constant $B$ is given by

$$
B \equiv\left[\Omega_{i} w_{j}^{k} \rho^{\rho-k}\left(\left(\frac{A}{\sigma}\right)^{\rho-k}\left(F^{x}\right)^{k-(\sigma-1)}\left(f^{x}\right)^{k+\rho(\sigma-1)} f^{-k}\right)^{\frac{1}{\sigma-1}}\right]^{\frac{1}{2 k-\rho}}
$$


Differentiation of Eq. (30)

The partial derivative of the implicit Function $F\left(\varphi^{d}, \tau\right)$ in Eq. (30) with respect to $\tau$ is given by

$$
\frac{\partial F\left(\varphi^{d}, \tau\right)}{\partial \tau}=-\left(\frac{-k^{2}}{(2 k-\rho) \rho}\right) f^{x} B^{-k}(1+\tau)^{\frac{-k^{2}}{(2 k-\rho) \rho}-1}>0
$$

and with respect to $\varphi^{d}$, respectively, by

$$
\frac{\partial F\left(\varphi^{d}, \tau\right)}{\partial \varphi^{d}}=\frac{k^{2}}{2 k-\rho} \frac{\delta f_{e}}{(\Theta-1)}\left(\varphi^{d}\right)^{\frac{k^{2}}{2 k-\rho}-1}-\left(\frac{-\left(k^{2}-k \rho\right)}{2 k-\rho}\right) f\left(\varphi^{d}\right)^{\frac{-\left(k^{2}-k \rho\right)}{2 k-\rho}-1}>0
$$

The strictly positive signs follow from the assumption that $k>\sigma$. 


\section{References}

Antweiler, Werner, Brian R. Copeland, and M. Scott Taylor (2001) 'Is free trade good for the environment?' American Economic Review 91(4), 877-908

Bernard, Andrew B., Stephen J. Redding, and Peter K. Schott (2007) 'Comparative advantage and heterogeneous firms.' Review of Economic Studies 74(1), 31-66

Cole, Matthew A., and Robert J. R. Elliott (2003) 'Determining the trade-environment composition effect: the role of capital, labor and environmental regulations.' Journal of Environmental Economics and Management 46(3), 363-383

_ (2008) 'Industrial activity and the environment in China: An industry-level analysis.' China Economic Review 19(3), 393-408

Cole, Matthew A., Robert J. R. Elliott, and Kenichi Shimamoto (2005) 'Industrial characteristics, environmental regulations and air pollution: an analysis of the UK manufacturing sector.' Journal of Environmental Economics and Management 50(1), 121-143

Copeland, Brian R. (2010) 'How does trade affect the environment?' In Is economic growth sustainable?, ed. G. Heal (Palgrave Macmillan) pp. 206-247

- (2011) 'Trade and the environment.' In Palgrave Handbook of International Trade, ed. D. Bernhofen, R. Falvey, D. Greenaway, and U. Kreickemeier (Palgrave Macmillan) pp. 423-496

Copeland, Brian R., and M. Scott Taylor (1994) 'North-south trade and the environment.' Quarterly Journal of Economics 109(3), 755-787

- (2003) Trade and the environment: Theory and evidence (Princeton Series in International Economics. Princeton and Oxford: Princeton University Press) 
Demidova, Svetlana, and Andrés Rodríguez-Clare (2009) 'Trade policy under firm-level heterogeneity in a small economy.' Journal of International Economics 78(1), 100-112

Eaton, Jonathan, Samuel Kortum, and Francis Kramarz (2011) 'An anatomy of international trade: Evidence from French firms.' Econometrica 79(5), 1453-1498

Frankel, Jeffrey A., and Andrew K. Rose (2005) 'Is trade good or bad for the environment? Sorting out the causality.' Review of Economics and Statistics 87(1), 85-91

Grossman, Gene M., and Alan B. Krueger (1993) 'Environmental impacts of a North American Free Trade Agreement.' In The Mexico-U.S. Free Trade Agreement, ed. P. M. Garber (Cambride, MA: The MIT Press) pp. 13-56

Gürtzgen, Nicole, and Michael Rauscher (2000) 'Environmental policy, intra-industry trade and transfrontier pollution.' Environmental \& Resource Economics 17, 59-71

Haupt, A. (2006) 'Environmental policy in open economies and monopolistic competition.' Environmental 83 Resource Economics 33(2), 143-167

Haupt, Alexander (2000) 'Environmental product standards, international trade and monopolistic competition.' International Tax and Public Finance 7(4-5), 585-608

Holladay, J. Scott (2010) 'Are exporters mother nature's best friends?' Mimeo

Mazzanti, Massimiliano, and Roberto Zoboli (2009) 'Environmental efficiency and labour productivity: Trade-off or joint dynamics? A theoretical investigation and empirical evidence from Italy using NAMEA.' Ecological Economics 68(4), 1182-1194

McAusland, Carol (2010) 'Globalization's direct and indirect effects on the environment.' In Globalisation, Transport and the Environment, ed. Nils A. Braathen (OECD) pp. 31-54 
Melitz, Marc J. (2003) 'The impact of trade on intra-industry reallocations and aggregate industry productivity.' Econometrica 71(6), 1695-1725

Melitz, Marc J., and Daniel Trefler (2012) 'Gains from trade when firms matter.' Journal of Economic Perspectives 26(2), 91-118

Pflüger, Michael (2001) 'Ecological dumping under monopolistic competition.' Scandinavian Journal of Economics 103(4), 689-706

Rauscher, Michael (1997) International trade, factor movements, and the environment (Oxford and New York: Oxford University Press, Clarendon Press)

Sturm, Daniel M. (2003) 'Trade and the environment: a survey of the literature.' In Environmental Policy in an International Perspective, ed. L. Marsiliani, M. Rauscher, and C. Withagen (Kluwer Academic Publisher) pp. 119-149 